\title{
Use of Aquaporins to Achieve Needed Water Purity on the International Space Station for the Extravehicular Mobility Unit Space Suit System
}

\author{
Terry R. Hill ${ }^{1}$ and Brandon W. Taylor ${ }^{2}$ \\ NASA Johnson Space Center, Houston, TX, 77058 and Baylor University Waco, Texas, 76798
}

\begin{abstract}
With the retirement of the U.S. Space Shuttle fleet, the supply of extremely high quality water required for the Extravehicular Mobility Unit (EMU) space suit cooling on the International Space Station (ISS) will become a significant operational hardware challenge in the very near future. One proposed solution is the use of a filtration system consisting of a semipermeable membrane embedded with aquaporin proteins, a special class of transmembrane proteins that facilitate passive, selective transport of water in vivo. The specificity of aquaporins is such that only water is allowed through the protein structure, and it is this novel property that invites their adaptation for use in water filtration systems, specifically those onboard the ISS for the EMU space suit system. These proteins are also currently being developed for use in terrestrial filtration systems.
\end{abstract}

\section{Nomenclature}

$\begin{array}{ll}\text { A/L CLR } & \text { (or ALCLR) AirLock Coolant Loop Remediation } \\ \text { ARC } & =\text { NASA's Ames Research Center } \\ \text { Ar/R } & =\text { aromatic/arginine } \\ \text { BTU } & =\text { British thermal unit } \\ \text { CFU } & =\text { Colony Forming Unit } \\ \text { DMSD } & =\text { dimethylsilanediol } \\ \text { EMU } & =\text { Extravehicular Mobility Unit } \\ \text { EVA } & =\text { Extravehicular Activity } \\ \text { FPS } & =\text { Fan-Pump-Separator } \\ \text { FPU } & =\text { Fluid Pumping Unit } \\ \text { ISS } & =\text { International Space Station } \\ \text { LCVG } & =\text { Liquid Cooling and Ventilation Garment } \\ \text { MgO } & =\text { Magnesium Oxide } \\ \text { MSFC } & =\text { NASA's Marshall Space Flight Center } \\ \text { MF } & =\text { multi-filtration } \\ \text { mL } & =\text { milliliter } \\ \text { PLSS } & =\text { Primary Life Support Subsystem } \\ \text { PWR } & =\text { Payload Water Reservoir } \\ \text { S/N } & =\text { serial number } \\ \text { SWME } & =\text { Spacesuit Water Membrane Evaporator } \\ \text { TOC } & =\text { Total Organic Carbon } \\ \text { TOCA } & =\text { Total Organic Carbon Analyzer } \\ \text { UIA } & =\text { Umbilical Interface Assembly } \\ \text { WPA } & =\text { Water Processing Assembly }\end{array}$

\footnotetext{
${ }^{1}$ EMU Space Suit Subsystem Engineer, Crew and Thermal Systems Division, 2101 NASA Parkway, Houston, TX 77058/Mail Stop EC5, terry.hill-1@nasa.gov.

2 Student Researcher, Baylor University, brandon_taylor@baylor.edu 


\section{Introduction}

$\mathrm{T}$ he International Space Station (ISS) Extravehicular Mobility Unit (EMU) space suit system was originally developed for use on the U.S. Space Shuttle as a method to mitigate some failure scenarios where the Shuttle payload bay doors fail to close and lock properly. This system has since evolved from a suit designed to help secure the Shuttle to one capable of capturing and repairing satellites, and enabling astronauts to assemble and maintain the ISS. While the EMU as a whole has a proven track record for robust performance, the suit's thermal cooling loop has historically been very sensitive to the purity of water in both the feed supply and thermal loop. With the retirement of the U.S. Space Shuttle fleet, the supply of extremely-high-quality water required for the EMU space suit cooling on the ISS will become a significant operational hardware support challenge in the very near future.

One proposed solution is the use of a filtration system consisting of a semipermeable membrane embedded with aquaporin proteins, a special class of transmembrane proteins that facilitate passive, selective transport of water. The specificity of aquaporins is such that only water is allowed through the protein structure, and it is this novel property that invites their adaptation for use in water filtration systems, specifically those onboard the ISS for the EMU space suit system. This paper will discuss the current water quality requirements for the ISS EMU space suit, some of the challenges with regard to the future water supply for the EMU, and possible solutions by utilizing the characteristics of aquaporins based upon some of the current implementations of aquaporins that are being developed for terrestrial filtration systems.

\section{Overview of the Extravehicular Mobility Unit Water Loop ${ }^{23}$}

The ISS EMU space suit has life support systems to regulate the thermal and breathable-gas environment inside of the suit. The suit's thermal loop, which will be the focus of discussion in this paper, is comprised of a two-part water loop: the liquid transport circuit that circulates water through the liquid cooling garment that is worn by the astronaut; and the feed water circuit.

\section{A. Liquid Transport Circuit}

The flow path of the EMU liquid transport circuit originates at the EMU Fan-Pump-Separator (FPS) (a combined unit that has the breathable-gas ventilation loop fan that is magnetically coupled to the liquid transport circuit water pump, and provides the capability to separate water condensation from the ventilation loop and dump the condensation into the closed-loop water system), which then delivers water to the thermal control valve that provides the astronaut the ability to control the amount of water that will bypass the sublimator. At the thermal control valve, a portion of the water is allowed to flow through the liquid cooling ventilation garment and back to the FPS. The water that is allowed to bypass the thermal control valve will flow to the sublimator, discharge heat upon sublimation, and provide the heat exchange function between the liquid transport circuit and the feed water circuit.

Once initially charged with water, the liquid transport circuit is subject to the biological challenges common to most water systems. Microorganisms are naturally present in the hardware at some level—despite the best attempts at disinfection. Additionally, contamination can be accumulated directly from the astronaut via the hardware that removes exhalation condensate from the ventilation loop. Whereas some level of biological growth is tolerated, the liquid transport circuit must be filtered and iodinated every 90 days after the initial charge with water.

\section{B. Feed Water Circuit}

The feed water circuit provides the capability to reject the heat from the EMU that has been either generated by the astronaut's metabolic processes, from the EMU's avionic systems, from the life support mechanical systems, or from the external environment. Three reservoir tanks (one large and two small) that are initially charged with approximately 10 pounds (aprox. 4.8 quarts) of ultrapure water supply the feed water circuit. A detailed discussion regarding the necessity of the ultrapure water is addressed in subsequent sections. The feed water circuit provides enough water to support cooling for an 8-hour extravehicular activity (EVA). In the event that the 10 pounds of water from the primary tank is prematurely depleted, the reserve tanks can provide an additional 30 minutes of cooling capability at a 1000 British thermal unit (BTU)/hr metabolic rate, enough time to allow the astronaut to return to the ISS airlock.

Water flows from the feed water tanks to the sublimator, which acts as a heat exchanger between the feed water circuit and the liquid transport circuit. The sublimator operates at the triple point of water, where the three phases of water are present. Upon exposing the EMU to the vacuum of space, water flow to the sublimator from

2 
the feed water system is initiated and forms a layer of ice on the surface of the sublimator that is exposed to vacuum. After the ice layer is formed, water from the feed water circuit remains liquid by picking up the heat from the liquid transport loop via the heat exchanger in the sublimator. The heat removed from the liquid transport loop is dissipated into space via the sublimation of the sublimator ice layer. As the ice sublimates, the voids left behind in the ice layer are filled with additional water from the feed water circuit.

A porous plate that contains thousands of near-microscopic holes is required as part of the ability of the sublimator to allow and control the rate at which water sublimates to vacuum. Due to the very small diameter of the holes in the porous plate (8-10 $\mu \mathrm{m}$ diameter), fouling by feed water impurities is of utmost concern and has historically been the source of thousands of man-hours to investigate sublimator failure. Therefore, unlike the less-sensitive transport water circuit, the feed water circuit requires a water supply of the utmost purity. It is our belief that the natural water transport function of aquaporins can be applied to achieve the needed purity.

\section{Overview of the Mechanics of Aquaporins}

\section{A. Principles of Reverse/Forward Osmotic Filtration Relevant to use of Aquaporins}

Fresh water is an important resource on any space mission. A variety of purification techniques are available to meet demand where continued resupply from terrestrial sources proves problematic or inconvenient. In particular, mechanical filtration systems - in which contaminants are physically separated from influent waterare of interest because of their low energy cost per unit water produced, as compared to other methods such as distillation. Mechanical systems rely on pumps to force wastewater through the filter apparatus, which are typically a fine mesh or polymeric membrane, with apertures small enough to exclude dissolved solute and particulates while allowing the passage of water. ${ }^{1,2}$ Filtration methods are often classified based on the size of the apertures they use, which correlates with the size (and importantly, proportion) of contaminants that can be removed. From large to small pore size (low to high filtration capability), the methods currently in use are microfiltration $\left(0.1\right.$ to $\left.10 \times 10^{-6} \mathrm{~m}\right)$, ultrafiltration $\left(0.1\right.$ to $\left.0.01 \times 10^{-6} \mathrm{~m}\right)$, nanofiltration $\left(0.01\right.$ to $\left.0.001 \times 10^{-6} \mathrm{~m}\right)$, and reverse osmosis $\left(0.0001\right.$ to $\left.0.001 \times 10^{-6} \mathrm{~m}\right) .{ }^{1}$ With larger meshes, as in microfiltration, filtration is achieved primarily through a physical "skimming out" of contaminants. However, as the size of pores and contaminants decreases, the effects of the filter's chemical composition become non-negligible. ${ }^{3}$ For example, electrostatic repulsion from a membrane that carries a charge within its operational $\mathrm{pH}$ range can contribute to the exclusion of like-charged solutes, as with a positively charged membrane and $\mathrm{Mg}^{2+}$ ions dissolved in the influent water.

Of the conventional types of mechanical filtration, reverse osmosis is the most attractive in terms of the size of contaminants removed, and accordingly sees wide use in commercial desalinization plants worldwide. ${ }^{1,2}$ Though these plants require pretreatment of source water to mitigate fouling, ${ }^{4}$ the membranes they use are capable of rejecting a very high proportion of dissolved salts, up to 99.8 percent under certain conditions. $^{2}$

For certain specialized applications, however, even this high level of purity is insufficient. Aquaporin-based filtration has the potential to achieve essentially complete rejection of solute from influent water and therefore provides a potential solution.

Aquaporins are a special class of transmembrane protein that act as selectively permeable channels for water and, as varies among isoforms, other solutes. ${ }^{5,6}$ Aquaporins are widely conserved in nature, being found in almost every organism, and are represented in every major taxonomic division. In humans, one of the numerous isoforms is involved in the concentration of urine in the kidneys, ${ }^{6}$ while another isoform is present in bacteria and helps

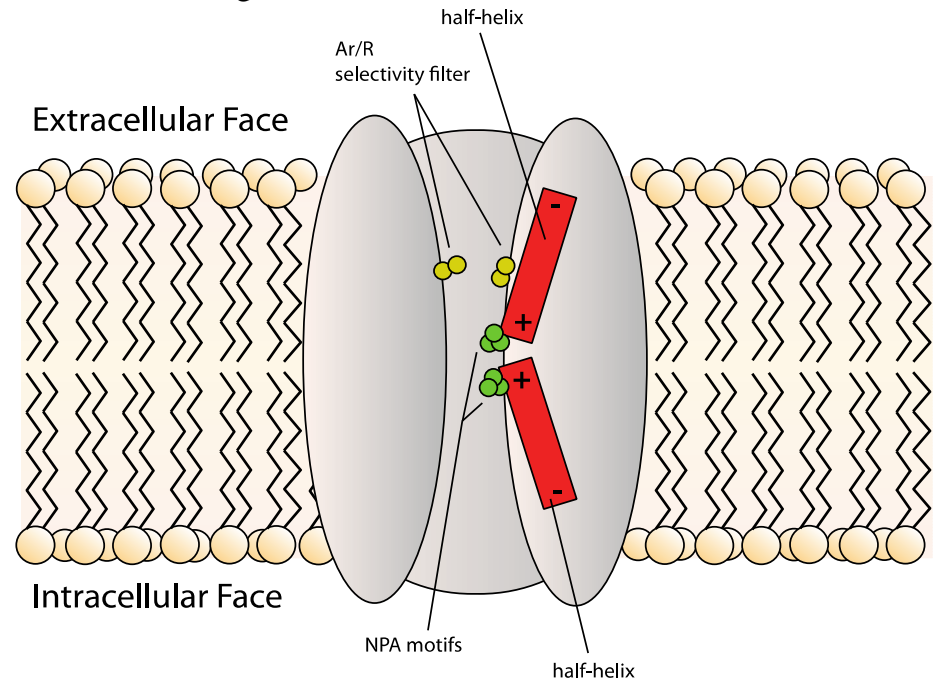

Figure 1. Schematic of an aquaporin protein embedded in a section of lipid bilayer, the fundamental structure of the cell membranes in which aquaporins are naturally found. Two half-helices (red) produce a net positive charge near the center of the aquaporin channel, resulting in an electrostatic barrier to the passage of positively charged solutes. The Ar/R filter and two NPA motifs (yellow and green respectively) provide additional transport selectivity. 


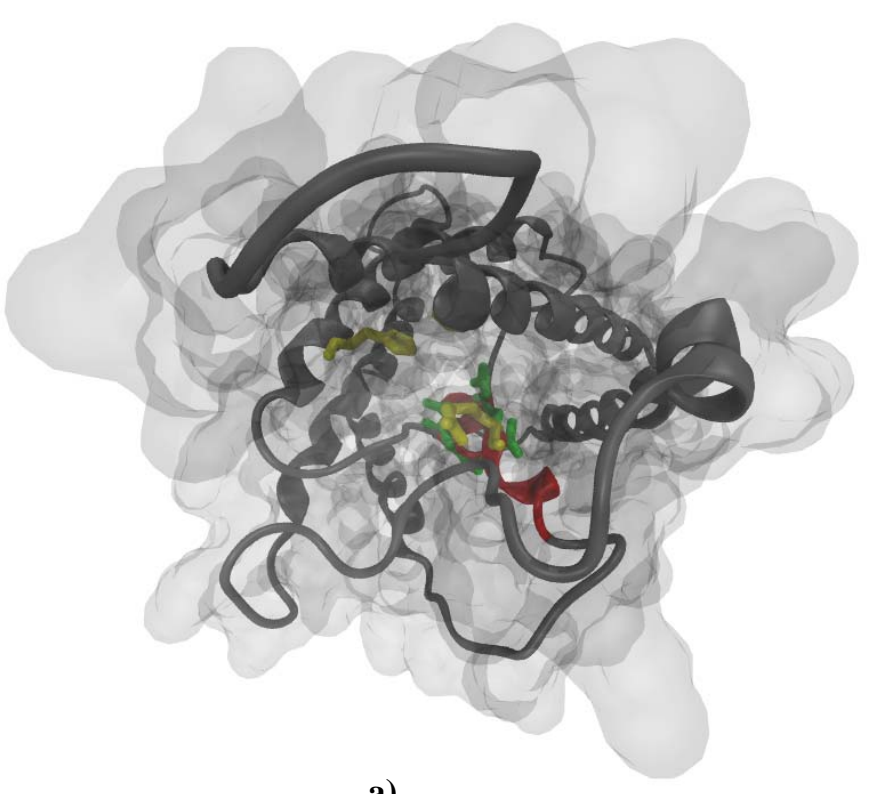

a)

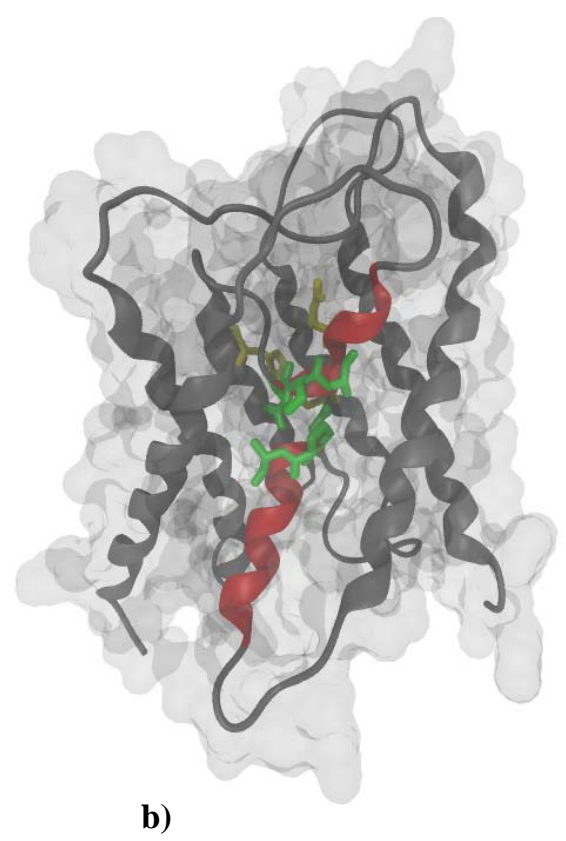

b)

Figure 2a-b. Three-dimensional structure of the AQP-1 isoform of aquaporin protein, viewed from the extracellular "top" of the protein (a) and one "side" of the protein (b). In both views, the black ribbon represents the protein's backbone, while surrounding gray area represents the protein's surface. Highlighted in red are the two half-helices that contribute to a net positive charge at the center of the aquaporin's water channel. The amino acids of the Ar/R selectivity filter and two NPA motifs are drawn as stick-structures (yellow and green, respectively).

diffuse osmotic gradients that might otherwise rupture the cell. The majority of aquaporins are entirely specific for water and allow its passage at speeds approaching the diffusion-limited rate. ${ }^{5}$ However, certain isoforms are known to permit the passage of other solutes (including glycerol, urea, and arsenite), ${ }^{7}$ which limits the utility of these isoforms in water filtration schemes.

The water-specificity that is seen in most aquaporins results from certain shared structural features, illustrating the recurring biological theme of "form determining function." In keeping with their role as passive transporters of water, aquaporins are constructed much like a pipe, with a central cavity enclosed by a protein "shell." ${ }^{5-7}$ The central cavity is shaped like an hourglass, with its widest diameter $(\sim 15 \AA)$ reached at either end, with the midpoint of the channel reaching $\sim 3.8 \AA \times 3.4 \AA{ }^{5}$ approximately the Van Der Waals diameter of water. This constriction results in a physical, size-based exclusion of solutes larger than the channel, and partially accounts for the transport specificity of aquaporin. Structural comparison indicates that the hourglass shape is conserved across all aquaporins. A cluster of several amino acids, known as the aromatic/arginine (Ar/R) selectivity filter, protrudes into the central constriction of the channel and further mediates specificity. This cluster is composed of hydrophobic aromatic amino acids and the amino acid arginine, ${ }^{8}$ with the latter carrying a partial positive charge at physiological $\mathrm{pH}$. Additionally, two half-helices in the protein strand create a permanent dipole that contributes further to the positive potential in the center of the channel (Fig. 1) ${ }^{7,9,24}$ This charge is thought to provide an electrostatic energy barrier to the translocation of cations through the aquaporin structure. ${ }^{7}$ Two triplets of the amino acids asparagine, proline, and alanine also appear within the aquaporin protein sequence. These triplets, known as NPA motifs, form hydrogen bonds with incoming water molecules via a side group on each asparagine. As the water molecules pass by the NPA motifs, they are reoriented in such a way as to prevent protons from jumping between adjacent waters, thus_-remarkably_preventing proton passage through the channel. It has been thought that this reorientation is due to the hydrogen bonding with the NPA motifs ${ }^{6}$, though results from one molecular dynamics study suggest that reorientation may be caused by the dipole from the two half-helices. ${ }^{9}$

Aquaporins associate into tetramers in the membranes of living cells, creating a cluster of four independently functioning channels that are arranged in such a way as to create an additional, central pore. ${ }^{5}$ This central pore appears to be largely impermeable, although molecular dynamics simulations predict that molecular oxygen and carbon dioxide may pass through, at least in the AQP-1 isoform of aquaporin. It has been observed, however, that aquaporin-mediated gas flow is low in comparison to passage through the surrounding cell membrane, with its much larger surface area. ${ }^{8}$ Moreover, gaseous impurities, which are readily removed by the Primary Life Support Subsystem (PLSS) water/gas separator, are not a likely source of sublimator failure. 
The transport specificity of aquaporin protein can thus be applied in filtration systems to provide water of exceptional purity. To date, at least one lab has managed to incorporate aquaporins (bacterial aquaporin-Z) into a synthetic polymer membrane while retaining their transport functionality. ${ }^{4}$ One other, commercial entity, Aquaporin A/S, is currently pursuing aquaporin-based filtration and has a prototype in testing at NASA's Ames Research Center (ARC). We present in the following section data from filtration tests on the prototype.

\section{B. Filtration Feasibility Assessment}

Performance characteristics of an aquaporin-based filter manufactured by the Danish company Aquaporin A/S (http://www.aquaporin.dk/), was tested in a collaborative effort with NASA's ARC and Johnson Space Center (JSC).To minimize testing costs for this feasibility assessment, the test setup utilized a brine solution on the exit side of the filter to aid in the migration of the water molecules through the filter; however, a reverse-osmosis implementation would likely be employed in applying this technology to the EMU system.

The feed solution, consisting of 550 milliliter (mL) with an initial concentration shown in Table 1, was created in the JSC Crew and Thermals Systems Division water laboratory to a pre-defined constituent concentrations to simulate a non-desirable feed water solution that might be encountered on the ISS based upon water samples returned in the past. The brine solution was made by dissolving 58.44 grams $/ \mathrm{mol}$ of $\mathrm{NaCl}$ into $442 \mathrm{~mL}$ of deionized water in the one liter brine tank to yield a $2 \mathrm{M} \mathrm{NaCl}$ solution.

The constituent concentrations of the feed and exit solutions were taken pre- and post-test to determine the effectiveness of the Aquaporin filter's permeability to allow only the pure water molecules to translate through the aquaporin impregnated membrane. The expected results would show a concentration per unit volume of the feed solution and a dilution of the exit brine solution due to the increase in water on the exit side of the filter. The test hardware set-up is shown in Fig. 3 a \& b where the Spacesuit Water Membrane Evaporator (SWME) feed stock solution $^{*}$ is on the left and the brine solution is on the right in Fig. 3a. The Aquaporin filter (Fig. 3b) was placed in a test block to secure the feed and exit solution hardware and to control the filtration membrane area to 0.00042 $\mathrm{m}^{2}$. Both the feed stock and the brine solutions have suction and discharge lines and a pump to provide circulation to both sides of the aquaporin filter during testing.

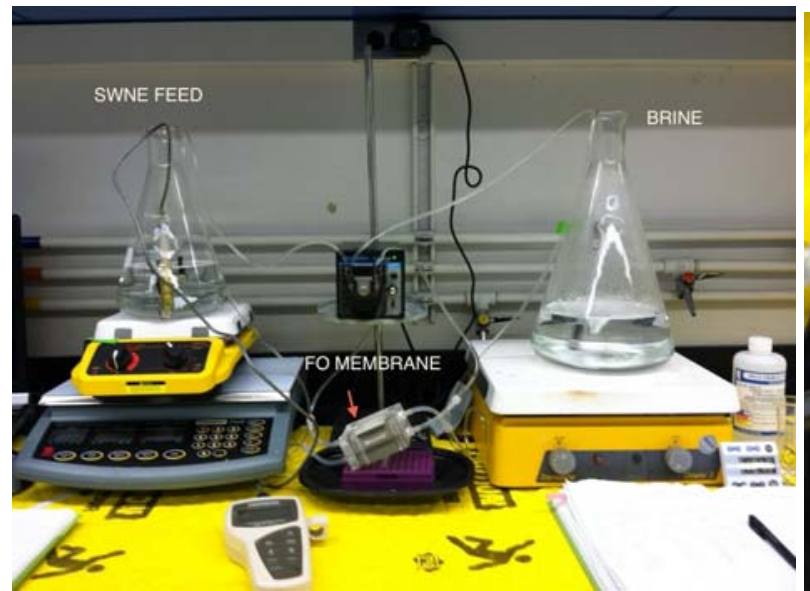

a)

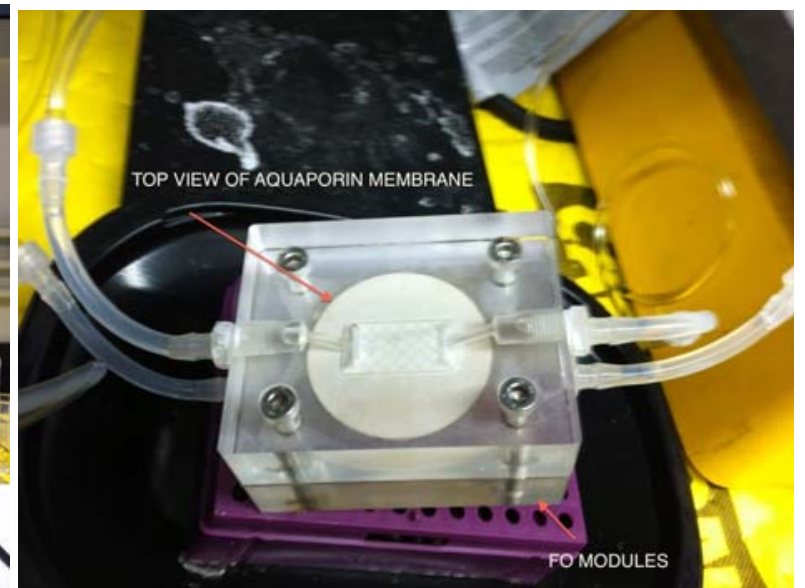

b)

Figures 3a and b. (a) Test set up for feasibility of aquaporin membrane filtering. (b) Test fixture holding the commercial Aquaporin filter (center) with feed solution circulating on the left and brine solution circulating on the right.

The preliminary Aquaporin filter testing results (see raw data in Tables 1 and 2 in the Appendix) as of the publication of this paper indicate a linear solute and ion concentration as a function of test run time (Fig. 4). The

\footnotetext{
* The Spacesuit Water Membrane Evaporator (SWME) feed stock solution is made from a recipe used by the advanced space suit life support systems development group at JSC. This standardized solution represents challenging water with some typically expected contaminates that can be used for testing advanced heat rejection system for long-durations.
} 
analysis of the post filtration brine solution indicates a dilution of the ammonium, potassium and chloride as would be expected by the migration of water from the feed stock solution via the osmotic process. This corresponds to the volumetric measurements of a decrease in feed stock volume and corresponding increase brine solution volumes in Table 2.
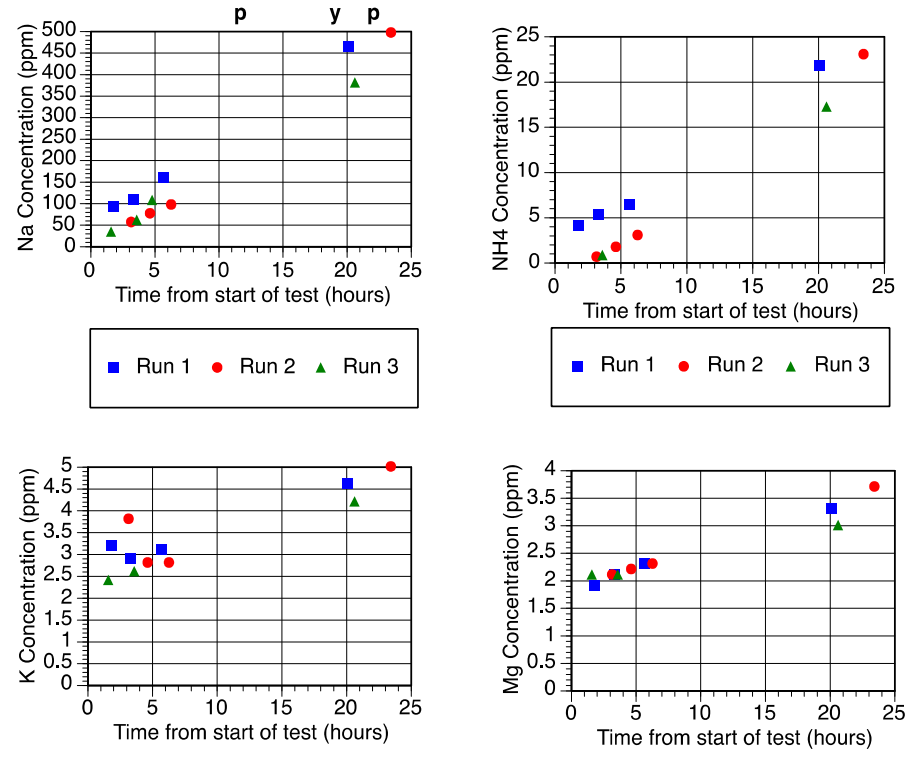

- Run 1 Run 2、Run 3

- Run 1 Run 2 A Run 3
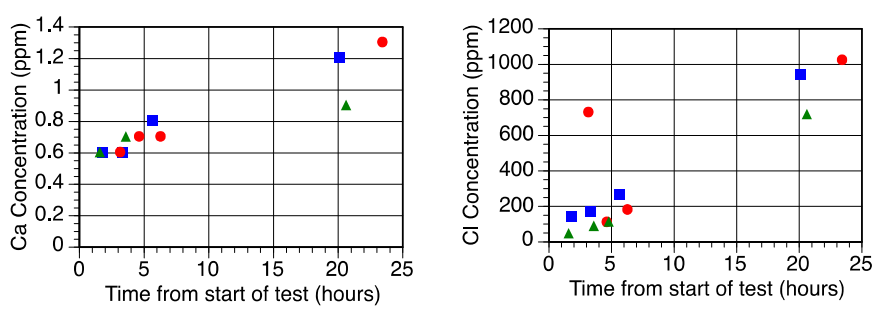

- Run 1 - Run 2 A Run 3

- Run1 Run 2 A Run 3

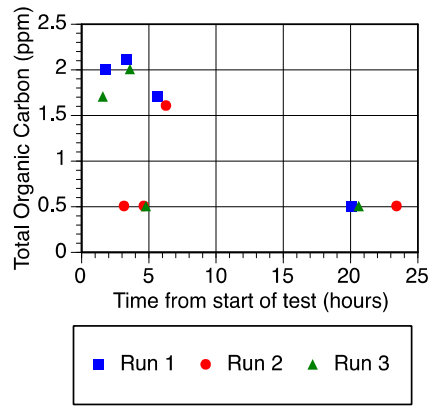

Figures 4. Solute concentration in feed stock solution versus time from start of filtration test. Data are separated by replicate.

There are a few notable observations in reviewing the preliminary data with regard to ammonium, sodium and chloride feed stock concentrations and decrease of ammonium brine solution concentrations. With the significant increase of these solutes in the feed stock solutions and corresponding decrease in the brine solutions, there was some concern that there might be some leaching or break through the membrane for this solutes. It should be noted that due to the comparatively high levels of $\mathrm{NaCl}$ in the brine solution, definitive readings of the ammonium and other salts was difficult. Using the data, as system mass analysis for these constituents was performed using the individual test run concentration measurements and multiplying by the associated solution volume. However, the variability in the results did not show consistent trending that might imply a migration from the brine to the feed stock solutions or by any possible leaching from the membrane material.

The preliminary results were inconclusive regarding the effectiveness of the Aquaporin filters to block the migration of TOC to the brine solution. Subsequent testing of the test samples for TOC concentrations is being performed as of the publishing of this paper by Wyle Labs of Houston. 
The data shown in Table 3 validates the sample constituent analysis technique that was used by Ames, as their results were similar to those in four of the test runs where the samples were analyzed by from Wyle Labs of Houston.

However, the testing to determine the amount of TOC specification attributed to IRA67 resin extract had not be returned from the testing labs at the time of the publication of this paper.

\section{Changes to the Extravehicular Mobility Unit Water Supply Quality}

\section{A. Past Issues}

As has been documented in prior papers from the EMU community, the EMU sublimator is highly prone to fouling of the porous plate by various contaminants. These contaminants historically have fallen within two distinct categories: (1) particulates (organic and inorganic) and (2) film-forming substances (amphipathic molecules ${ }^{14}$ and organic acids/surfactants [abietic acids]), ${ }^{15}$ with the latter category believed to have a tendency to link together and "knot," thus forming a sublimation-impeding film on the effluent side of the plate and blocking the sublimator pores, which typically are between 8-10 $\mu \mathrm{m}$.

Examples of the earliest sublimator contamination issues occurred early in the program, when the Liquid Cooling and Ventilation Garment (LCVG) employed the Tygon water tubing used during the Apollo Program. Contamination released by this material plugged not only system filters but also the sublimator porous plates. A change of tubing material to nuclear cross-linked ethylene vinyl acetate solved this problem. Later, aluminum corrosion products became the next cause of performance loss; these contaminants were eliminated after a change from aluminum (valve module, valves, etc.) to stainless steel. ${ }^{17}$

\section{Extravehicular Mobility Unit Contamination Due to International Space Station Airlock Cooling Loop}

Following the Space Shuttle Columbia accident February 1, 2003, three EMUs (serial number (S/N) 3005, 3011, and 3013) were left onboard the ISS and began to experience significant performance degradation and 
failure $^{\dagger}$ within approximately a year ${ }^{\ddagger}$ after being initially charged with water and launched to the ISS. ${ }^{11}$ Prior to the accident, the EMUs had been returned to the ground via the Shuttle within 6-12 months after arrival on the ISS. The maintenance practices in place at the time, the unknown issues with the ISS Airlock Heat Exchanger hardware, and the long duration on the ISS facilitated the failure of the units via the clogging of filters by organic and inorganic residues and subsequent seizing of the FPS assembly.

One analysis on components of the EMU hardware water loop found microbial counts up to $10^{6}-10^{8}$ Colony Forming Units (CFU)/mL. ${ }^{10}$ The microorganisms were of the commonly encountered genus Ralstonia, whose member species are known to colonize water systems and form biofilms that foul gas traps, filters, and other fine orifices. ${ }^{10}$

The inorganic contaminant contributors were identified to be the ISS Airlock Heat Exchanger with $\mathrm{BNi}_{3}$ braze alloy and/or the EMU valve module and various plumbing components that had corrosion-resistant steel surfaces. ${ }^{10}$ These coatings resulted in the Gas Trap (Item 141) accumulations of inorganic particulates consisting of nickel, silicon, and aluminum and the gas trap cover plugged with iron oxide.

As a result of this series of failures associated with the prolonged time between the cleaning of the water loop, the time between activation of the systems and the contaminants introduced to the EMU from the ISS, the EMU Airlock (AL) Coolant Loop Remediation (CLR) hardware was developed and placed into service. The A/L CLR (ALCLR) hardware is a kit of filters and connectors that allow the EMU water loop to be purged of particulates and biological contaminates. The kit consists of an ion exchange filter, a $3 \mu \mathrm{m}$ filter and an iodine biocide filter that is used to reduce the biological organic count after the cleaning (scrubbing) has occurred. ${ }^{11}$ As intended, incorporation of the ALCLR hardware into the maintenance plan resulted in a significant reduction in the total organic and inorganic buildup in the EMU system. ${ }^{12}$

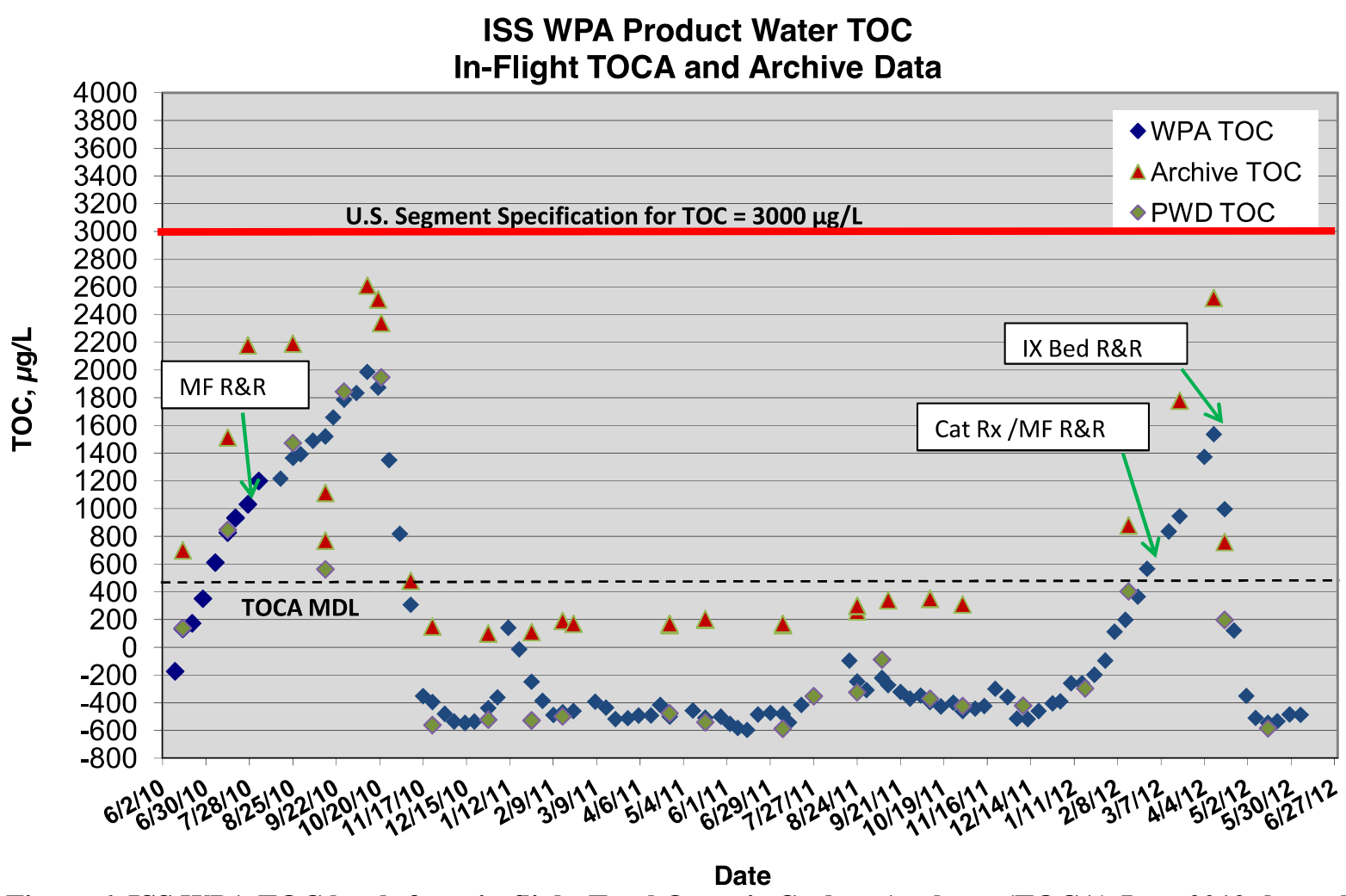

Figure 6. ISS WPA TOC levels from in-flight Total Organic Carbon Analyzer (TOCA) June 2012 through March of 2012.

\footnotetext{
${ }^{\dagger}$ S/N 3005 had cooling problems prior to EVA on 19 May 2003 and again on 19 May 2004, S/N 3011 temporarily lost cooling during suit donning on 19 May 2004, and S/N 3013 had cooling problems starting on 28 May 2003..$^{10,11}$

${ }^{\ddagger}$ S/N 3005 was charged with water on 8 October 2002, S/N 3011 charged on 26 April 2002, and S/N 3013 was charged on 26 April 2002.
} 
2. International Space Station Water: Contamination with IRA-67 and Variation in Total Organic Compounds

Starting in June 2010, the ISS water system began to experience a significant increase in Total Organic Carbon (TOC). In August of that year, it was decided to obtain a water sample for groundside testing with the minisublimator test hardware to determine whether the rising TOC would have an adverse affect on the EMU. The increased TOC trending continued until late in October, at which point the levels quickly began to fall and return to normal (see Fig. 6) ${ }^{19}$ It should be noted that there has been a second upward trending in the ISS TOC values similar to what was seen in June-October of 2011. While the levels are still below the maximum allowable level, the situation will be closely monitored.

During the testing to determine the nature of the TOC contaminants, it was noticed that dimethylsilanediol (DMSD)-type compound was the primary constituent, and IRA-67 extract ion was later identified as the source that adversely impacted sublimator performance ${ }^{22}$. DMSD has been observed in Space Station humidity condensate archived samples over many years; however, the cause for the rise in levels still remains unexplained.

An extensive testing program was enacted to determine the source of the IRA-67 extract and the level of the compound the sublimator would tolerate without failing or adversely affecting sublimator performance. The source of the contaminant was determined to be the ISS water MF filter beds ${ }^{25}$. After testing and analysis of two subsequent water sample returns from the ISS, it was determined that the IRA-67 leachant (aqueous extract) drops to tolerable levels by the time roughly 6,000 lbs of water have passed through the MF beds (see Fig. 7) ${ }^{22}$. This indicates that if the available Payload Water Reservoirs (PWRs) are filled with Water Processing Assembly (WPA) water after approximately 6,000 lbs of water has passed through the MF beds, this will provide sufficient reserves - given the number of currently planned EVAs_-for roughly 2 years of operation and will significantly reduce the risk of sublimator performance degradation.

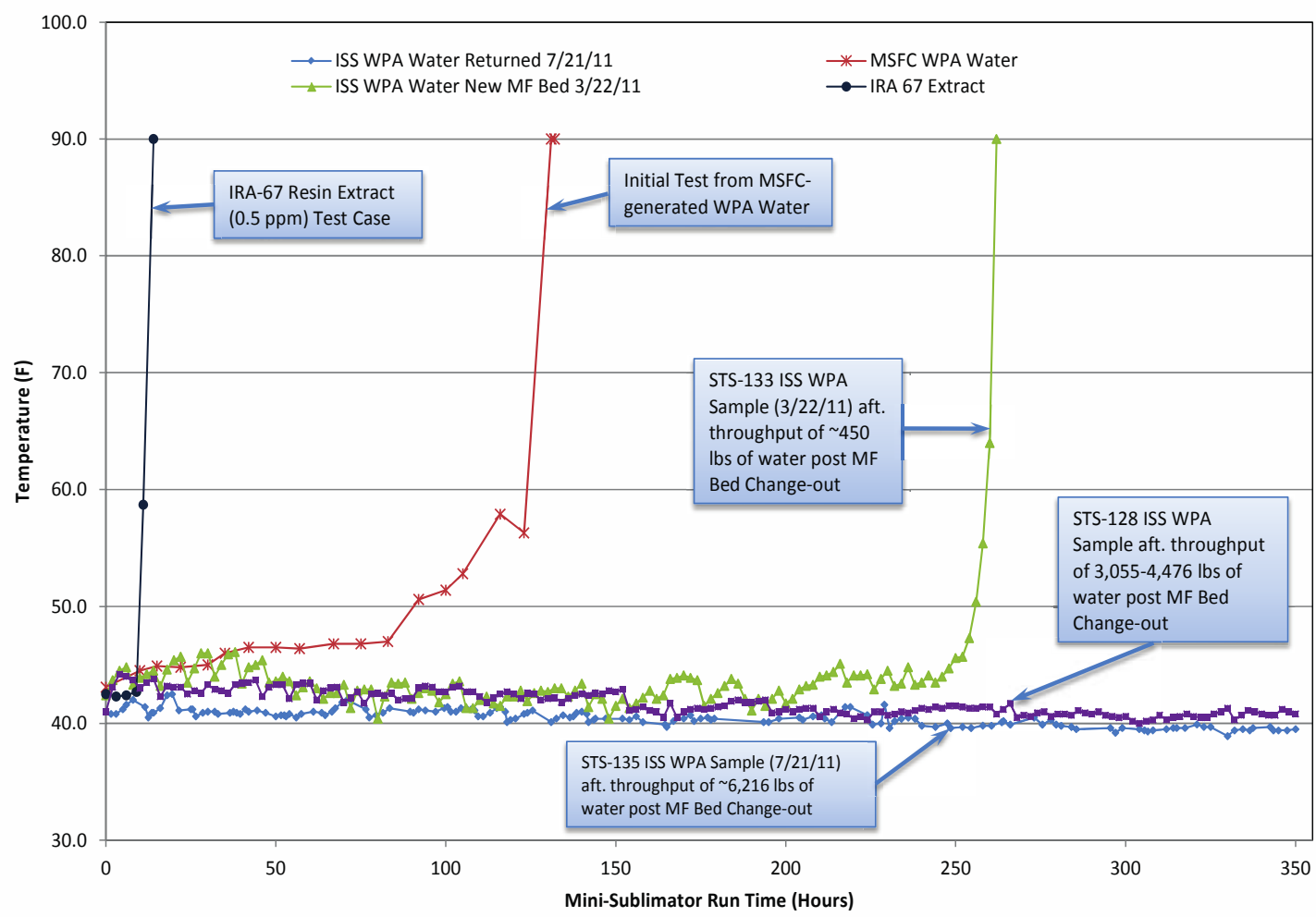

Figure 7. Testing results of EMU mini-sublimator hardware testing with ISS water samples returned on Shuttle missions STS-128, 133 \& 135 along with MSFC-generated test water and an aqueous solution of IRA-67 resin extract to test the sublimator sensitivity to varying levels of IRA-67 resin extract. 


\section{B. Near-Term and Future Changes in Water Supply and Potential Impacts}

\section{Obsolescence and Future Supplier Supportability Issues}

The current EMU system is projected to remain in service until at least 2020, and likely as late as 2028. By that time, suit components and designs will be more than 30 years old. Coupled with an aging system is the risk of hardware material or component obsolescence. This obsolescence can come in the form of material being deleted from the vendor's catalogue unexpectedly, change in formulation, discovery of toxicity issues and shortage of raw material, to name only a few scenarios. The EMU program has been witness to all of these issues in the past, and these issues will likely continue into the future. Two system hardware components are already in review by the EMU life support hardware provider, Hamilton Sundstrand (Windsor Locks, CT), and for which there is a new or yet to be defined vendor. When the vendor for the EMU hardware is no longer in existence or is no longer interested in providing the hardware, and refurbishment and life-extension activities are no longer an option, a new vendor and possibly a new design will be required.

\section{Water Tank Bladder Material}

The water tank structure for the EMU consists of multiple cavities in the PLSS that are lined with a bladder, originally Neoprene. Not long after going into service, the sublimator's performance began to degrade and it eventually failed altogether. It was discovered that the sublimator pores were being blocked with the abietic acid constituents of the Neoprene latex. ${ }^{14}$

A new bladder material was formulated, a change to a Rucothane-based material, which appeared to meet the requirements; however, later testing revealed leachants were comparable to the Neoprene with regard to the sublimator performance. ${ }^{17}$ Finally, a material that contained Fluorel ${ }^{\S}$ and met the EMU performance requirements was procured between 1990-91, and was considered a lifetime buy. That in itself is not of significant interest other than the fact that the source of a magnesium oxide constituent (MAGLITE ${ }^{\circledR}$ D) of the Fluorel was comprised of 95\% concentrations per unit volume. In 2010, it was determined that the life-time buy would not meet the new planned usage of the EMU and a new order was placed with a new vendor that attempted to create the bladders using the processes of the original vendor.

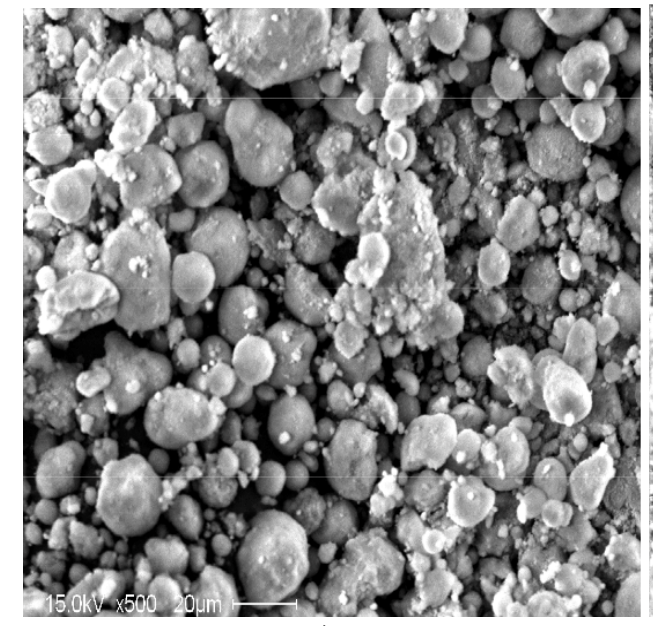

a)

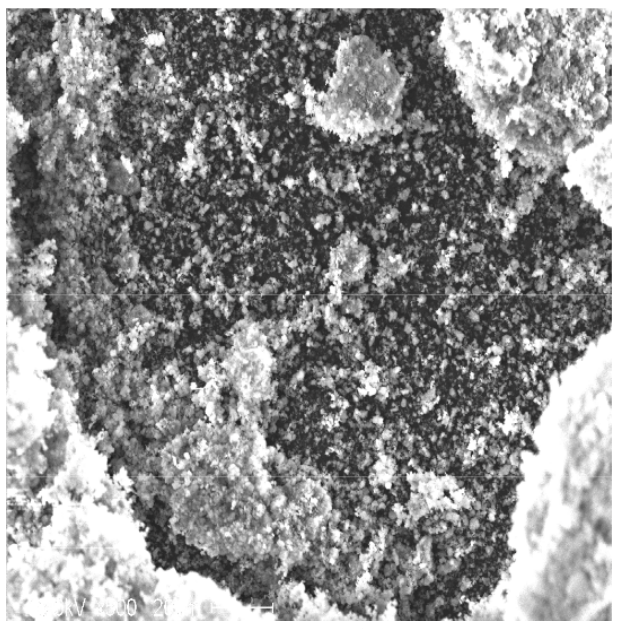

b)

Figure 8. (a) “Old” MAGLITE ${ }^{\circledR} \mathrm{Y}$ at $500 \mathrm{X}$ with relatively low surface area (95\% purity) “10-20 $\mathrm{\mu m}$ spheres”. (b) “New” MAGLITE ${ }^{\circledR} \mathrm{Y}$ at $500 \mathrm{X}$ with relatively high surface area ( $99 \%$ purity) "Very fine flakes". ${ }^{20}$

However, upon receipt of the new bladders the sublimators began to fail once again. Through extensive testing and investigation it was discovered that the original feed stock of MAGLITE ${ }^{\circledR}$ D was no longer available (the last batch was produced in 2004) so the bladder manufacture found a new source of ore; however, thorough sample

\footnotetext{
$\S$ The use of Fluorel is familiar to NASA as it was used late in the Apollo Program to replace the polyurethane boot sole on the space suit. ${ }^{16}$
}

10

American Institute of Aeronautics and Astronautics 
analysis later found that the new ore had a 99\% MAGLITE ${ }^{\circledR}$ Y purity. The difference between the MAGLITE ${ }^{\circledR}$ $\mathrm{D}$ and $\mathrm{Y}$ is a designation of the surface area of the material.

The bladders with the new formulation and higher purity MAGLITE ${ }^{\circledR} \mathrm{Y}$ resulted in increased deposition of magnesium oxide (MgO) on the sublimator porous plate. Further investigation of MAGLITE ${ }^{\circledR} \mathrm{Y}$ more recently purchased was smaller in size and flat in contrast to the prior circular, larger particles (see Fig. 8). It was thought that the stacking of the flat smaller particles actually provided less surface area to react with the HF generated during polymerization. The result was that the resultant Fluorel had poor physical properties and excess MgO was available as a leachate to impact sublimator performance (plugging mode). Increase in purity may have resulted in loss of a "natural" cross-link activation with naturally occurring calcium, ${ }^{18}$ which lead to much more free $\mathrm{MgO}$ to leach into the water and deposit on the sublimator porous plate. An extensive search for stores of MAGLITE ${ }^{\circledR} \mathrm{D}$ at other vendors of the original material supplier did not result in any remaining material.

A substitute MgO was found, smaller in size and circular but had a long-chain fatty acid (hexadecanoic acid) used as a surface dispersant to keep the small particles of $\mathrm{MgO}$ from agglomerating. The hexadecanoic acid leached out and adversely impacted sublimator performance (film-forming mode).

New formulations using Starmag ${ }^{\circledR}$ appear promising, but, at this time, certification of replacement bladder material is incomplete.

\section{Water Supply from the International Space Station}

While the ISS water system is currently working as expected, the fact remains that water is one of the most corrosive natural substances, and the ISS will be more than 30 years old by the year 2028. It can be expected that the water system will experience corrosion, changes in leachants with age-dependent changes in material properties, and variable organic compositions as three decades of organic growth and evolution takes place in the ISS water loop.

Additionally, the composition of the ISS water will continually change due to reclamation of human waste and humidity recovery, and the ever-changing chemicals due to different metabolisms, diets, personal hygiene and makeup products, cleaners and onboard experiments, and material off-gassing.

With the ever-changing water composition that we can expect in the future and the highly sensitive sublimator porous plate, a host of potential contaminants (“unknown unknowns") may not be realized until new sublimator performance degradation or failures occur.

\section{Application of Aquaporins to Provide Required Extravehicular Mobility Unit Water Quality}

\section{A. Pre-processing of International Space Station Water Prior to Suit Usage}

The proposed utilization of the aquaporin technology would be as a pre-processor of the ISS water prior to loading into the EMU system. Testing still remains to be completed; however, if the performance of the filters is as expected, the aquaporin technology will provide the single most important and cost-effective hardware implementation to ensure a dependable quality water supply for the EMU.

Initial thoughts would be to design a filter cartridge that would interface between the hardware that currently connects the $\mathrm{PWR}^{\S}$ and the UIA/FPU hardware. This implementation would not require a redesign of any of the existing EMU or ISS hardware but would require some positive pressure to force the unfiltered water, via reverse-osmosis filtration, through the aquaporin filter. Due to the pressure required to facilitate the filtration, a membrane would have to be incorporated that could not only bind with the aquaporin channels but also withstand the required pressures. One such (artificial) membrane, proposed for a similar situation where aquaporins were needed in a reverse-osmosis implementation, should be considered for future prototypes and testing.

“...a synthetic membrane to house these proteins has been created that is composed of polymerized ABA triblock copolymer monomers. This polymer, PMOXZ-PDMS-PMOXZ, consists of a hydrophobic core set between two

\footnotetext{
$\S$ The PWR is the term for water bags developed for on-orbit ISS usage to temporarily store water either for transport to the ISS or for storage on the ISS. PWRs have been tested and proven to allow any iodination to last up to three years before appreciable organic growth is observed.
} 
hydrophilic groups that mimic the electrostatic conditions and thickness (about $5 \mathrm{~nm}$ ) of a natural lipid bilayer. ... Of course, the synthetic membrane is much more durable than lipid and can hold its shape under pressure once the special methacrylate end groups on the hydrophilic blocks have been crosslinked to one another by irradiation with $254 \mathrm{~nm}$ UV light." 21

A second potential implementation would be as a new filter in the current ALCLR hardware as a replacement for or augmentation of the current $3 \mu \mathrm{m}$ filter to achieve the highest water quality possible for the EMU liquid transport circuit. However, before this can be determined possible, a feasibility assessment will have to be performed to determine if the pressure drop of the filter will make this a viable option.

\section{B. Potential In-Suit Filtering Applications}

Finally, another possible implementation would be to incorporate an aquaporin-based filter into either the liquid transport or the feed water loop of the EMU. Similar to the ALCLR option, pressure drop and life-cycle analysis of the filter technology must be assessed before any feasibility determination can be made. If the technology proves viable, in-suit filtering has the potential to provide unprecedented water quality in the EMU and would have dramatic positive implication for the longevity of the EMU water loops and sublimator.

\section{Conclusion}

With the retirement of the Space Shuttle fleet, the near cost-prohibitive nature of launching water to the ISS for use by only the EMU suits, the aging of the ISS water system, the time-varying composition of the ISS water, and the highly sensitive heat rejection system of the EMU, development of a method of affordably providing pure water to the EMU is imperative. The promising benefits of the aquaporin technology, if realized through further development, could provide a cost-effective source of ultrapure water required for the EMU and thus ensure U.S. EVA capability through the remaining life of the ISS. 


\section{Appendix}

Table 1. Aquaporin pre- and post-test solution constituent concentrations. Filtration testing was performed at NASA ARC and with the exception of the "JSC Water Lab Feed Stock" results, the postfiltration analysis was provided by Ames. FS $=$ Feed Stock, BD $=$ Brine Draw (post-test), bdl $=$ below detection limit.

\begin{tabular}{|c|c|c|c|c|c|c|c|c|c|c|c|c|}
\hline \begin{tabular}{|l|} 
Sample \\
Name/Constituent \\
Concentrations \\
(mg/L) \\
\end{tabular} & $\mathrm{Na}^{+}$ & $\mathrm{NH}_{4}^{+}$ & $\mathbf{K}^{+}$ & $\mathbf{M g}^{2+}$ & $\mathrm{Ca}^{2+}$ & $\mathrm{Cl}^{-}$ & $\mathrm{NO}_{2}$ & $\mathrm{Br}^{-}$ & $\mathrm{NO}_{3}^{-}$ & $\mathbf{P O}_{4}{ }^{3-}$ & $\mathrm{SO}_{4}{ }^{2-}$ & TOC \\
\hline $\begin{array}{l}\text { JSC Water Lab Feed } \\
\text { Stock }\end{array}$ & & $<0.05$ & 2.4 & 2 & .4 & 3.0 & & & 8.4 & & 2.6 & 0.48 \\
\hline Feed Stock Pre-Test & $<0.5$ & $<0.5$ & 2.2 & 2.0 & 0.9 & 3.1 & $<0.5$ & $<0.5$ & 7.2 & $<0.5$ & 2.3 & $<0.5$ \\
\hline \multicolumn{13}{|l|}{ Brine Draw Pre-Test } \\
\hline FS Run 1 Sample 1 & 90.9 & 4.1 & 3.2 & 1.9 & 0.6 & 136 & bdl & bdl & 7.9 & bdl & 2.3 & 2.0 \\
\hline FS Run 1 Sample 2 & 109 & 5.3 & 2.9 & 2.1 & 0.6 & 165 & bdl & bdl & 7.6 & bdl & 2.3 & 2.1 \\
\hline FS Run 1 Sample 3 & 158 & 6.4 & 3.1 & 2.3 & 0.8 & 262 & bdl & bdl & 8.1 & bdl & 2.6 & 1.7 \\
\hline sFS Run 1 Sample 4 & 464 & 21.7 & 4.6 & 3.3 & 1.2 & 941 & bdl & bdl & 10.4 & bdl & 3.5 & $<0.5$ \\
\hline FS Run 2 Sample 1 & 55.7 & 0.6 & 3.8 & 2.1 & 0.6 & 727 & bdl & bdl & 7.4 & bdl & 2.2 & $<0.5$ \\
\hline FS Run 2 Sample 2 & 75.9 & 1.7 & 2.8 & 2.2 & 0.7 & 108 & bdl & bdl & 7.8 & bdl & 2.6 & $<0.5$ \\
\hline FS Run 2 Sample 3 & 96.3 & 3.0 & 2.8 & 2.3 & 0.7 & 178 & bdl & bdl & 9.5 & bdl & 3.0 & 1.6 \\
\hline FS Run 2 Sample 4 & 496 & 23.0 & 5.0 & 3.7 & 1.3 & 1021 & bdl & bdl & 11.6 & bdl & 4.1 & $<0.5$ \\
\hline FS Run 3 Sample 1 & 33.4 & bdl & 2.4 & 2.1 & 0.6 & 44.6 & bdl & bdl & 7.2 & bdl & 2.4 & 1.7 \\
\hline FS Run 3 Sample 2 & 60.7 & 0.8 & 2.6 & 2.1 & 0.7 & 85.5 & bdl & bdl & 7.9 & bdl & 2.6 & 2.0 \\
\hline FS Run 3 Sample 3 & 107 & bdl & bdl & bdl & bdl & 110 & bdl & bdl & bdl & bdl & bdl & $<0.5$ \\
\hline FS Run 3 Sample 4 & 380 & 17.2 & 4.2 & 3.0 & 0.9 & 716 & bdl & bdl & 10.5 & bdl & 3.6 & $<0.5$ \\
\hline BD Run 1 Sample 1 & 45070 & 428 & bdl & bdl & bdl & 84367 & bdl & bdl & bdl & bdl & bdl & \\
\hline BD Run 1 Sample 2 & 46810 & 546 & bdl & bdl & bdl & 89017 & bdl & bdl & bdl & bdl & bdl & \\
\hline BD Run 1 Sample 3 & 43208 & 350 & bdl & bdl & bdl & 81920 & bdl & bdl & bdl & bdl & bdl & \\
\hline BD Run 1 Sample 4 & 35867 & bdl & bdl & bdl & bdl & 65940 & bdl & bdl & bdl & bdl & bdl & \\
\hline BD Run 2 Sample 1 & 45749 & 492 & bdl & bdl & bdl & 88151 & bdl & bdl & bdl & bdl & bdl & \\
\hline BD Run 2 Sample 2 & 44347 & 388 & bdl & bdl & bdl & 85507 & bdl & bdl & bdl & bdl & bdl & \\
\hline BD Run 2 Sample 3 & 44590 & 372 & bdl & bdl & bdl & 91190 & bdl & bdl & bdl & bdl & bdl & \\
\hline BD Run 2 Sample 4 & 37557 & bdl & bdl & bdl & bdl & 71313 & bdl & bdl & bdl & bdl & bdl & \\
\hline BD Run 3 Sample 1 & 46077 & 493 & bdl & bdl & bdl & 88943 & bdl & bdl & bdl & bdl & bdl & \\
\hline BD Run 3 Sample 2 & 43834 & 339 & bdl & bdl & bdl & 101584 & bdl & bdl & bdl & bdl & bdl & \\
\hline BD Run 3 Sample 3 & 45560 & bdl & bdl & bdl & bdl & 90246 & bdl & bdl & bdl & bdl & bdl & $<0.5$ \\
\hline BD Run 3 Sample 4 & 36336 & bdl & bdl & bdl & bdl & 68191 & bdl & bdl & bdl & bdl & bdl & \\
\hline
\end{tabular}

ॠ Other JSC water lab constituent testing results not tested at Ames in mg/L: manganese: 0.02, iron: 0.06, nickel: 0.02, copper: 0.24 , zinc: 0.24 . 
Table 2. Additional post-filtration ARC tests results.

\begin{tabular}{|c|c|c|c|c|c|c|c|c|c|}
\hline Sample Name & $\begin{array}{c}\text { Date and } \\
\text { Time }\end{array}$ & $\begin{array}{l}\text { Total } \\
\text { Time } \\
\text { (hrs) }\end{array}$ & $\begin{array}{l}\text { Delta } \\
\text { Time } \\
\text { (hrs) }\end{array}$ & $\begin{array}{l}\text { Vol. of } \\
\text { Feed } \\
\text { (kg) }\end{array}$ & $\begin{array}{c}\text { Vol. of } \\
\text { Draw } \\
\text { (kg) }\end{array}$ & $\begin{array}{l}\text { Conductivity } \\
\text { running } \\
\text { Value of } \\
\text { Feed } \\
(\mathrm{mS} / \mathrm{cm})\end{array}$ & $\begin{array}{c}\text { Conductivity } \\
\text { running } \\
\text { Value of } \\
\text { Draw } \\
(\mathrm{mS} / \mathrm{cm})\end{array}$ & $\begin{array}{l}\text { Brine } \\
\Delta(\mathrm{L})\end{array}$ & $\begin{array}{c}\text { Rejection } \\
\text { (\%) }\end{array}$ \\
\hline FS Run 1 Sample 1 & $\begin{array}{c}5 / 14 / 2012 \\
14: 54\end{array}$ & 1.80 & 1.80 & 0.33 & 0.52 & 0.43 & 142.6 & 0.126 & 70.83 \\
\hline FS Run 1 Sample 2 & $\begin{array}{c}5 / 14 / 2012 \\
16: 24\end{array}$ & 3.30 & 1.50 & 0.31 & 0.54 & 0.59 & 143.7 & 0.106 & 85.10 \\
\hline FS Run 1 Sample 3 & \begin{tabular}{|c|}
$5 / 14 / 2012$ \\
$18: 45$
\end{tabular} & 5.65 & 2.35 & 0.29 & 0.56 & 0.79 & 141 & 0.146 & nd \\
\hline FS Run 1 Sample 4 & $\begin{array}{c}5 / 15 / 2012 \\
9: 10\end{array}$ & 20.07 & 14.42 & 0.20 & 0.65 & 2.33 & 125.1 & 0.146 & 86.60 \\
\hline FS Run 2 Sample 1 & $\begin{array}{c}5 / 15 / 2012 \\
14: 12\end{array}$ & 3.15 & 2.48 & 0.33 & 0.52 & 0.32 & 148.1 & 0.152 & 90.23 \\
\hline FS Run 2 Sample 2 & $\begin{array}{c}5 / 15 / 2012 \\
15: 40\end{array}$ & 4.62 & 1.47 & 0.31 & 0.54 & 0.38 & 143.5 & 0.152 & nd \\
\hline FS Run 2 Sample 3 & $\begin{array}{c}5 / 15 / 2012 \\
17: 19\end{array}$ & 6.27 & 1.65 & 0.29 & 0.56 & 0.52 & 143.4 & 0.152 & nd \\
\hline FS Run 2 Sample 4 & \begin{tabular}{|c|}
$5 / 16 / 2012$ \\
$10: 28$
\end{tabular} & 23.42 & 17.15 & 0.18 & 0.67 & 2.47 & 124.1 & -- & -- \\
\hline FS Run 3 Sample 1 & \begin{tabular}{|c|}
$5 / 16 / 2012$ \\
$14: 09$ \\
\end{tabular} & 1.57 & 1.57 & 0.33 & 0.52 & 0.17 & 145.2 & 0.152 & -- \\
\hline FS Run 3 Sample 2 & $\begin{array}{c}5 / 16 / 2012 \\
16: 10 \\
\end{array}$ & 3.58 & 2.02 & 0.31 & 0.54 & 0.33 & 143.5 & 0.136 & nd \\
\hline FS Run 3 Sample 3 & $\begin{array}{c}5 / 16 / 2012 \\
17: 21\end{array}$ & 4.77 & 1.18 & 0.29 & 0.56 & 0.40 & 141.5 & 0.136 & nd \\
\hline FS Run 3 Sample 4 & $\begin{array}{c}5 / 17 / 2012 \\
9: 11\end{array}$ & 20.60 & 15.83 & 0.20 & 0.65 & 1.82 & 123.8 & 0.136 & 62.39 \\
\hline
\end{tabular}

Table 3. Constituent analysis of ARC test samples provided by Wyle Labs of Houston using inductively coupled plasma mass spectrometry (ICP-MS).

\begin{tabular}{|l|c|c|c|c|c|c|c|c|c|c|c|c|}
$\begin{array}{l}\text { Sample } \\
\text { Name/Constituent } \\
\begin{array}{l}\text { Concentrations } \\
\text { (mg/L) }\end{array}\end{array}$ & $\mathbf{N a}^{+}$ & $\mathbf{N H}_{\mathbf{4}}{ }^{+}$ & $\mathbf{K}^{+}$ & $\mathbf{M g}^{2+}$ & $\mathbf{C a}^{2+}$ & $\mathbf{C l}^{-}$ & $\mathbf{N O}_{2}$ & $\mathbf{B r}$ & $\mathbf{N O}_{3}{ }^{-}$ & $\mathbf{P O}_{4}{ }^{3-}$ & $\mathbf{S O}_{4}{ }^{2-}$ & $\mathbf{T O C}$ \\
\hline FS Run 1 Sample 4 & 461 & -- & 3.71 & 3.0 & 0.93 & -- & -- & -- & -- & $<0.1$ & -- & 1.08 \\
\hline FS Run 2 Sample 4 & 490 & -- & 3.98 & 3.18 & 0.95 & -- & -- & -- & -- & $<0.1$ & -- & .767 \\
\hline FS Run 3 Sample 4 & 360 & -- & 3.48 & 2.74 & 0.81 & -- & -- & -- & -- & $<0.1$ & -- & .595 \\
\hline BD Run 1 Sample 4 & 35600 & -- & 1.36 & $<0.4$ & 1.14 & -- & -- & -- & - & $<0.4$ & -- & .464 \\
\hline BD Run 2 Sample 4 & 35200 & -- & 1.3 & $<0.4$ & 0.92 & -- & -- & -- & -- & $<0.4$ & -- & .190 \\
\hline BD Run 3 Sample 4 & 45200 & -- & 1.25 & $<0.4$ & 0.80 & -- & -- & -- & -- & $<0.4$ & -- & .322 \\
\hline
\end{tabular}




\section{Acknowledgments}

The authors would like to acknowledge and extend sincere thanks to Justine Tra-My Richardson and Michael T. Flynn of the NASA ARC for performing the aquaporin feasibility assessment and Daniel B. Gazda of Wyle Science, Technology and Engineering Group in Houston, Texas for performing the IRA-67 extract testing of the post-filtration samples. Thanks to Niklas Adam of the JSC Crew and Thermal Systems Division Water Lab who created the test feed solution. Additionally, we would like to thank John Steele of Hamilton Sundstrand, Windsor Locks for his peer reviews, support in tracking down some of the historical information for this paper and for supplying a water/IRA-67 solution for the testing.

\section{References}

${ }^{1}$ Greenlee, L. F., Lawler, D. F., Freeman, B. D., Marrot, B., and Moulin, P. (2009) Reverse Osmosis Desalination: Water Sources, Technology, and Today's Challenges, Water Research 43, 2317-2348.

${ }^{2}$ Lee, K. P., Arnot, T. C., and Mattia, D. (2011) A Review of Reverse Osmosis Membrane Materials for Desalination-Development to Date and Future Potential, Journal of Membrane Science 370, 1-22.

${ }^{3}$ Lee, S., and Lueptow, R. M. (2001) Reverse Osmosis Filtration for Space Mission Wastewater: Membrane Properties and Operating Conditions, Journal of Membrane Science 182, 77-90.

${ }^{4}$ Kumar, M., Grzelakowski, M., Zilles, J., Clark, M., and Meier, W. (2007) Highly Permeable Polymeric Membranes Based on the Incorporation of the Functional Water Channel Protein Aquaporin Z, Proceedings of the National Academy of Sciences 104, 20719 -20724.

${ }^{5}$ Savage, D. F., and Stroud, R. M. (2007) Structural Basis of Aquaporin Inhibition by Mercury, Journal of Molecular Biology 368, 607-617.

${ }^{6}$ Agre, P., and Kozono, D. (2003) Aquaporin Water Channels: Molecular Mechanisms for Human Diseases, FEBS Letters $555,72-78$.

${ }^{7}$ Törnroth-Horsefield, S., Hedfalk, K., Fischer, G., Lindkvist-Petersson, K., and Neutze, R. (2010) Structural Insights Into Eukaryotic Aquaporin Regulation, FEBS Letters 584, 2580-2588.

${ }^{8}$ Wang, Y., Cohen, J., Boron, W. F., Schulten, K., and Tajkhorshid, E. (2007) Exploring Gas Permeability of Cellular Membranes and Membrane Channels With Molecular Dynamics, Journal of Structural Biology 157, 534-544.

${ }^{9}$ Hashido, M., Ikeguchi, M., and Kidera, A. (2005) Comparative Simulations of Aquaporin Family: AQP1, AQPZ, AQP0 and GlpF, FEBS Letters 579, 5549-5552.

${ }^{10}$ Lewis J., Cole H., Cronin G., Gazda D., Steele J., "Extravehicular Mobility Unit (EMU) / International Space Station (ISS) Coolant Loop Failure and Recovery”, SAE-01-2240, 2006

${ }^{11}$ Reiss, J., "Summary Sequence of Events For SEMU 3013, 3011, and 3005”, Hamilton Sundstrand, PowerPoint presentation to NASA EVA project, 25 May 2004, (unpublished)

${ }^{12}$ Steele J., Rector T., Gazda D., Lewis J., "Performance of the Extravehicular Mobility Unit (EMU) Airlock Coolant Loop Remediation (A/L CLR) Hardware Phase II”, SAE-01-2541, 2009

${ }^{13}$ Steele J., Rector T., Gazda D., Lewis J., "Performance of the Extravehicular Mobility Unit (EMU) Airlock Coolant Loop Remediation (A/L CLR) Hardware - Final”, AIAA-2011-5274, 41st International Conference on Environmental Systems 17-21 July 2011, Portland, Oregon

${ }^{14}$ Steele, John, "White Paper - Desensitize Sublimator to Film Forming Contaminants", white paper to NASA EVA project, 4 January 2012 (unpublished)

${ }^{15}$ Steele J., Schneider S., Wilde R., “Space Station Water for EMU? Subscale Sublimator Testing”, SAE 932183

16 Lutz C., Stutesman H., Carson M., and McBarron II J., "Apollo Experience Report - Development Of The Extravehicular Mobility Unit”, National Aeronautics and Space Administration’s Lyndon B. Johnson Space Center, NASA TN D-8093, November 1975

${ }^{17}$ Hamilton Sundstrand Corporation, “EMU Requirements Evolution”, SEMU-66-017B, NASA's Extravehicular Activity (EVA) Systems Contract, September 30, 2005, Rev. B,

${ }_{18}^{18}$ Auman J., "PLSS WTS Bladder Risk”, NASA’s EVA Program Management Review presentation, June 9, 2011.

${ }^{19}$ Steele, J., "ISS Water Processor Assembly (WPA) Water for EMU Feed-water Post Shuttle”, NASA's EVA Program Management Review presentation, January 21, 2011.

${ }^{20}$ Steele, J. and Oehler, B., "PLSS WTS Bladder Feasibility Status”, NASA's EVA Program Management Review presentation, January 21, 2011.

${ }^{21}$ Montemagno, Carlo, "Water Purifcation by Reverse Osmosis using an Aquaporin Z-embedded Polymer Vesicle Network”, California NanoSystems Institute (CNSI) UCLA, 2005 Annual Research Report Annotated Research Papers Including Collaboration Detail, 2005.

${ }^{22}$ EVAM-00925, OneEVA Program, DO 9R1, “Test Report - EMU Sublimator Performance using Flight-Generated WPA Water Returned on STS-135”, January 19, 2012

${ }^{23}$ NASA Extravehicular Mobility Unit (EMU) LSS/SSA Data Book, Hamilton Sundstrand Corporation (HSC), revision P, September 2010.

${ }^{24}$ Fujiyoshi, Y., Mitsuoka, K., de Groot, B. L., Philippsen, A., Grubmüller, H., Agre, P., and Engel, A. (2002) Structure and Function of Water Channels, Current Opinion in Structural Biology 12, 509-515. 
${ }^{25}$ EVAM-00870, OneEVA program, DO 9, "DO 9 Test Report - EMU Sublimator Performance using Flight-Generated WPA Water Drawn Soon after an MF Bed Change-out”, July 13, 2011. 